\title{
Produtividade e qualidade de melão sob manejo com água de salinidade crescente $^{1}$
}

\author{
Cícero Pereira Cordão Terceiro Neto ${ }^{2}$, Hans Raj Gheyi ${ }^{3}$, \\ José Francismar de Medeiros ${ }^{4}$, Nildo da Silva Dias ${ }^{4}$, Marcos de Sousa Campos ${ }^{4}$
}

\begin{abstract}
Melon yield and quality under management with increasing water salinity

In semi-arid regions, irregular rainfall and scarcity of good quality water contribute to the use of saline water for irrigation. In this context, this study aimed to investigate the effects of saline water use in the yield and quality of melon fruits. Treatments consisted of two melon cultivars (Sancho - $\mathrm{C}_{1}$ and

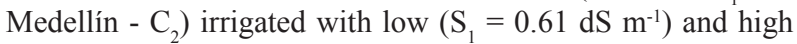
$\left(\mathrm{S}_{2}=4.78 \mathrm{dS} \mathrm{m}^{-1}\right)$ salinity water levels, for each phenological stage. The experimental design was split-plot randomized blocks, with six irrigation management strategies and two cultivars (6x2), with four replications. The results showed that the total and commercial number of fruits were influenced by the saline water management strategies. The irrigation management with good quality water, during two days, followed by saline water, for one day, enabled the commercial production of melon, with a reduction of $33 \%$ in the good quality water use.
\end{abstract}

KEY-WORDS: Cucumis melo L.; saline stress; environmental impact.

\section{INTRODUÇÃO}

No Rio Grande do Norte, a produção de melão se concentra na microrregião de Mossoró, em área de influência da Chapada do Apodi. Na região polarizada por Mossoró, parte da água utilizada para irrigação provém de poços artesianos profundos, que, apesar da boa qualidade, apresenta alto custo de obtenção, o qual, às vezes, inviabiliza seu uso na agricultura (Medeiros et al. 2003). Entretanto, há, também, poços abertos no aquífero calcário Jandaíra, que, mesmo apresentando custo de obtenção mais baixo, possui água com níveis de salinidade elevada.

\section{RESUMO}

Em áreas semiáridas, a irregularidade de chuvas e a escassez de água de boa qualidade contribuem para o uso de água salina para irrigação. Neste sentido, este trabalho objetivou investigar os efeitos do uso de água salina, na produção e qualidade de frutos de melão. Os tratamentos consistiram de duas cultivares de melão (Sancho - $\mathrm{C}_{1}$ e Medellín - $\mathrm{C}_{2}$ ), irrigadas com água de baixa $\left.\left(\mathrm{S}_{1}=0,61 \mathrm{dS} \mathrm{m}\right)^{-1}\right)$ e alta $\left(\mathrm{S}_{2}=4,78 \mathrm{dS} \mathrm{m}^{-1}\right)$ concentração salina, por cada fase fenológica da cultura. $\mathrm{O}$ delineamento experimental utilizado foi o de blocos ao acaso, em esquema de parcelas subdivididas, com seis estratégias de manejo de irrigação e duas cultivares $(6 \times 2)$, com quatro repetições. Os resultados evidenciaram que o número de frutos total e comercial foram influenciados pelas estratégias de manejo de água salina. A irrigação com água de boa qualidade, aplicada durante dois dias, seguida de água salina, por um dia, viabilizou a produção comercial de melão, com redução de $33 \%$ no uso de água de boa qualidade.

PALAVRAS-CHAVE: Cucumis melo L.; estresse salino; impacto ambiental.

Nos cultivos irrigados dessa região, tem sido comum a substituição de água de boa qualidade, isto é, de baixa condutividade elétrica, por água salobra de poços rasos, devido ao baixo custo. Uma alternativa para esta situação pode ser a mistura de águas de boa qualidade e de qualidade inferior, visando a aumentar a disponibilidade hídrica das propriedades agrícolas às culturas. Esta mistura pode permitir a irrigação de áreas maiores, mas não diminui o total de sais. Por esta razão, tornam-se imprescindíveis investigações sobre o uso racional destas águas, pois a sua utilização indiscriminada pode salinizar os solos (Aragão et al. 2009, Dias et al. 2011, Porto Filho et al. 2011, Terceiro Neto et al. 2012).

1. Trabalho recebido em nov./2012 e aceito para publicação em set./2013 (nº registro: PAT 21146).

2. Empresa de Assistência Técnica e Extensão Rural (Emater), Cabedelo, PB, Brasil. E-mail: cicerocordao@yahoo.com.br.

3. Universidade Federal do Recôncavo da Bahia (UFRB), Núcleo de Engenharia de Água e Solo, Cruz das Almas, BA, Brasil. E-mail: hans@pq.cnpq.br.

4. Universidade Federal Rural do Semiárido (Ufersa), Departamento de Ciências Ambientais e Tecnológicas, Mossoró, RN, Brasil.E-mails: jfmedeir@ufersa.edu.br, nildo@ufersa.edu.br, marcosufersa@hotmail.com. 
O excesso de sais no solo reduz a disponibilidade de água para as plantas (Soares et al. 2007), além de provocar desequilíbrio nutricional e toxicidade de íons específicos na planta (Ferreira Neto et al. 2007), a ponto de comprometer os rendimentos e a qualidade da produção. Entretanto, mesmo que, potencialmente, a irrigação exerça efeito sobre a salinização dos solos, isto não implica na transformação em solo salinizado, a ponto de torná-lo impróprio para a agricultura. Existem numerosos empreendimentos agrícolas no mundo, onde se tem obtido sucesso com cultivos irrigados com água salina, especialmente quando há monitoramento constante da salinidade do solo e a adoção de práticas de manejo da água salina com restrição de uso para a irrigação, a exemplo de investigações realizadas por Botía et al. (2005), Edelstein et al. (2005), Kusvuran et al. (2011) e Zong et al. (2011), com a cultura do meloeiro.

A tolerância de espécies agrícolas à salinidade pode variar entre cultivares de uma mesma espécie, com a fase fenológica da cultura e a estratégia de aplicação de água, ou seja, com a concentração salina da água (mistura das águas) e o tempo de exposição das plantas aos sais (Savvas et al. 2007, Costa et al. 2013).

Devido à importância econômica da cultura do meloeiro para o semiárido do Nordeste brasileiro e à necessidade de adequação de práticas de manejo de água salobra adaptada às condições edafoclimáticas locais, este trabalho objetivou avaliar a produção e a qualidade de frutos de melão das cultivares Sancho e Medellín, sob estratégias de manejo de irrigação com água salina.

\section{MATERIAL E MÉTODOS}

O experimento foi conduzido de 15 de setembro a 14 de novembro de 2009, em área da Fazenda Pedra Preta $\left(04^{\circ} 39^{\prime} 39,24^{\prime \prime}\right.$ S, 37 $23^{\circ} 13,31^{\prime \prime} \mathrm{W}$ e altitude de $60 \mathrm{~m}$ ), próxima a Mossoró $(\mathrm{RN})$. O clima da região, de acordo com a classificação de Köppen, adaptada ao Brasil, é do tipo "BSwh", que representa clima tropical semiárido muito quente e com estação chuvosa no verão, atrasando-se para o outono. A região apresenta temperatura média de $28,5^{\circ} \mathrm{C}$, com mínima de $22^{\circ} \mathrm{C}$ e máxima de $35^{\circ} \mathrm{C}$, precipitação pluvial média anual de $673,9 \mathrm{~mm}$ e umidade relativa do ar de 68,9\% (Carmo Filho \& Oliveira 1995).

O solo da área experimental é do tipo Argissolo Vermelho-Amarelo (Embrapa 1999). Foi coletada uma amostra composta do solo da área experimental, sendo esta conduzida ao Laboratório de Fertilidade e Nutrição de Plantas do Departamento de Ciências Ambientais e Tecnológicas da Universidade Federal Rural do Semiárido (Ufersa), para a caracterização química (Embrapa 1999) (Tabela 1). A condutividade elétrica do extrato de saturação do solo $\left(\mathrm{CE}_{\mathrm{es}}\right)$ foi determinada conforme Richards (1954).

As águas utilizadas na pesquisa foram provenientes do aquífero arenito Açu, com profundidade aproximada de $1.000 \mathrm{~m}$, caracterizado por apresentar água de baixa salinidade, e do aquífero calcário Jandaíra, com profundidade em torno de $80 \mathrm{~m}$, com água salina, tendo, como principais cátions predominantes, o $\mathrm{Na}^{+}, \mathrm{Ca}^{++}$e os ânions $\mathrm{HCO}_{3}^{-}$e $\mathrm{Cl}^{-}$. As características químicas das águas utilizadas no experimento encontram-se na Tabela 2.

Utilizou-se o melão Pele de Sapo (cultivares Sancho e Medellín), pertencente ao grupo inodorus. A cultivar Sancho caracteriza-se por apresentar frutos com a casca mosqueada, entre verde-escura e verde-clara, levemente enrugada, de formato ovalado, com polpa creme esverdeada, peso médio variando entre $1,8 \mathrm{~kg}$ e $2,5 \mathrm{~kg}$ e potencial para exportação (Morais et al. 2009). Já a cultivar Medellín apresenta frutos graúdos, de ótima conservação pós-colheita e qualidade (firmeza $\mathrm{e}^{\mathrm{o}} \mathrm{Brix}$ ), atendendo às exigências do mercado de exportação e doméstico. Apresenta ciclo tardio, bom vigor, formato oval, tamanho grande e ótima conservação pós-colheita (Medeiros et al. 2011). Estas cultivares foram escolhidas por apresentarem área de cultivo em expansão na região e, também, pela falta de informações técnicas, principalmente quanto à tolerância à salinidade, além de sua boa adaptação às condições climáticas da região e algumas características agronômicas, tais como tolerância a algumas doenças e pragas e excelente resistência pós-colheita.

Os tratamentos consistiram de irrigações de duas cultivares de melão do grupo inodorus (Sancho - $\mathrm{C}_{1}$ e Medellín - $\mathrm{C}_{2}$ ), em diferentes estratégias de uso de água de baixa $\left(\mathrm{S}_{1}=0,61 \mathrm{dS} \mathrm{m}^{-1}\right)$ e alta $\left(\mathrm{S}_{2}=4,78 \mathrm{dS} \mathrm{m}^{-1}\right)$ concentração salina, por cada fase fenológica da cultura (Tabela 3). Foi utilizado, como testemunha, o manejo de irrigação com a mistura de $37 \%$ da água $\mathrm{S}_{1}$ e $63 \%$ da água $\mathrm{S}_{2}-\mathrm{T}_{0}$ (manejo adotado pela Fazenda Pedra Preta, onde foi conduzido o experimento).

As fases de crescimento, floração, maturação dos frutos e colheita corresponderam, respectivamente, aos períodos compreendidos entre o transplantio e 
Tabela 1. Caracterização química do solo da área experimental (Mossoró, RN, 2009).

\begin{tabular}{|c|c|c|c|c|}
\hline \multirow{2}{*}{ Característica } & \multirow{2}{*}{ Unidade } & \multicolumn{3}{|c|}{ Profundidade $(\mathrm{cm})$} \\
\hline & & $0-15$ & $15-30$ & $30-45$ \\
\hline Cálcio & $\mathrm{cmol} \mathrm{kg}^{-1}$ & 2,76 & 1,37 & 1,27 \\
\hline Magnésio & $\mathrm{cmol}_{\mathrm{c}}^{\mathrm{c}} \mathrm{kg}^{-1}$ & 1,29 & 2,25 & 1,82 \\
\hline Sódio & $\mathrm{cmol}_{\mathrm{c}} \mathrm{kg}^{-1}$ & 0,15 & 0,10 & 0,10 \\
\hline Potássio & $\mathrm{cmol}_{\mathrm{c}}^{\mathrm{c}} \mathrm{kg}^{-1}$ & 0,14 & 0,13 & 0,07 \\
\hline S & $\mathrm{cmol}_{\mathrm{c}} \mathrm{kg}^{-1}$ & 4,34 & 3,85 & 3,26 \\
\hline Hidrogênio & $\mathrm{cmol} \mathrm{kg}^{-1}$ & 0,00 & 0,00 & 0,00 \\
\hline Alumínio & $\mathrm{cmol}_{\mathrm{c}} \mathrm{kg}^{-1}$ & 0,00 & 0,00 & 0,00 \\
\hline CTC & $\mathrm{cmol}_{\mathrm{c}}^{\mathrm{c}} \mathrm{kg}^{-1}$ & 4,34 & 3,85 & 3,36 \\
\hline PST $^{*}$ & $\%$ & 3,45 & 2,59 & 2,97 \\
\hline Carbonato de cálcio & Qualitativo & Ausência & Ausência & Ausência \\
\hline Carbono orgânico & $\mathrm{g} \mathrm{kg}^{-1}$ & 4,50 & 5,20 & 5,20 \\
\hline Matéria orgânica & $\mathrm{g} \mathrm{kg}^{-1}$ & 7,70 & 9,00 & 9,00 \\
\hline Nitrogênio & $\mathrm{g} \mathrm{kg}^{-1}$ & 0,40 & 0,50 & 0,50 \\
\hline Fósforo assimilável & $\mathrm{mg} \mathrm{kg}^{-1}$ & 50,80 & 50,70 & 50,60 \\
\hline $\mathrm{pH} \mathrm{H}_{2} \mathrm{O}_{(1: 2,5)}$ & - & 7,24 & 7,00 & 7,06 \\
\hline CE solo-água ${ }_{(1: 2,5)}$ & $\mathrm{dS} \mathrm{m}^{-1}$ & 0,21 & 0,17 & 0,13 \\
\hline $\mathrm{pH}_{\mathrm{es}}$ & - & 7,08 & 6,92 & 6,92 \\
\hline $\mathrm{CE}_{\mathrm{es}}$ & $\mathrm{dS} \mathrm{m}^{-1}$ & 0,94 & 0,85 & 0,46 \\
\hline Cloreto & $\operatorname{mmol}_{c} L^{-1}$ & 3,50 & 3,75 & 2,00 \\
\hline Carbonato & $\operatorname{mmol}_{c} L^{-1}$ & 0,00 & 0,00 & 0,00 \\
\hline Bicarbonato & $\operatorname{mmol}_{c}^{c} L^{-1}$ & 4,00 & 4,00 & 2,40 \\
\hline Sulfato & $\operatorname{mmol}_{c} \mathrm{~L}^{-1}$ & Ausência & Ausência & Ausência \\
\hline Cálcio & $\operatorname{mmol}_{\mathrm{c}} \mathrm{L}^{-1}$ & 3,75 & 2,50 & 1,50 \\
\hline Magnésio & $\operatorname{mmol}_{\mathrm{c}}^{\mathrm{c}} \mathrm{L}^{-1}$ & 6,37 & 7,50 & 3,87 \\
\hline Potássio & $\operatorname{mmol}_{c} L^{-1}$ & 0,69 & 0,69 & 0,35 \\
\hline Sódio & $\operatorname{mmol}_{c}^{c} L^{-1}$ & 3,84 & 3,94 & 2,74 \\
\hline RAS** & $\left(\mathrm{mmol} \mathrm{L}^{-1}\right)^{0,5}$ & 1,67 & 1,76 & 1,67 \\
\hline Classe do solo & \multicolumn{4}{|c|}{ Sem problemas de salinidade } \\
\hline
\end{tabular}

$* \mathrm{PST}=(\mathrm{Nat} / \mathrm{CTC}) 100 ; * * \mathrm{RAS}=\mathrm{Na}^{+} /\left[\left(\mathrm{Ca}^{+2}+\mathrm{Mg}^{+2}\right) / 2\right]^{1 / 2}$.

Tabela 2. Características das águas utilizadas no experimento (Mossoró, RN, 2009).

\begin{tabular}{llccc}
\hline Característica & Unidade & Água $\mathrm{S}_{1}$ & Água $\mathrm{S}_{2}$ & $\begin{array}{c}\text { Água } \\
\text { misturada }\end{array}$ \\
\hline $\mathrm{CE}$ & $\mathrm{dS} \mathrm{m}^{-1}$ & 0,61 & 4,78 & 3,21 \\
$\mathrm{pH}$ & - & 6,67 & 6,40 & 6,75 \\
$\mathrm{~K}$ & $\mathrm{mmol}_{\mathrm{c}} \mathrm{L}^{-1}$ & 0,49 & 0,12 & 0,28 \\
$\mathrm{Na}$ & $\mathrm{mmol}_{\mathrm{c}} \mathrm{L}^{-1}$ & 2,46 & 22,06 & 13,78 \\
$\mathrm{Ca}$ & $\mathrm{mmol}_{\mathrm{c}} \mathrm{L}^{-1}$ & 1,91 & 14,70 & 9,98 \\
$\mathrm{Mg}$ & $\mathrm{mmol}_{\mathrm{c}} \mathrm{L}^{-1}$ & 1,46 & 6,17 & 5,34 \\
$\mathrm{CO}$ & $\mathrm{mmol}_{\mathrm{c}} \mathrm{L}^{-1}$ & 0,00 & 0,00 & 0,00 \\
$\mathrm{HCO}$ & $\mathrm{mmol}_{\mathrm{c}} \mathrm{L}^{-1}$ & 3,77 & 4,75 & 4,59 \\
$\mathrm{Cl}$ & $\mathrm{mmol}_{\mathrm{c}} \mathrm{L}^{-1}$ & 1,83 & 38,87 & 23,55 \\
$\mathrm{SO}_{4}$ & Qualitativo & Ausência & Presença & Presença \\
$\sum$ cátions & $\mathrm{mmol}_{\mathrm{c}} \mathrm{L}^{-1}$ & 6,32 & 43,05 & 29,38 \\
$\sum$ ânions & mmol $_{\mathrm{c}} \mathrm{L}^{-1}$ & 5,60 & 43,62 & 28,14 \\
$\mathrm{RAS}$ & $\left(\mathrm{mmol} \mathrm{L}^{-1}\right)^{0,5}$ & 1,89 & 6,82 & 4,97 \\
\hline
\end{tabular}

Tabela 3. Estratégias de manejo de irrigação, com água de baixa $\left(\mathrm{S}_{1}=0,61 \mathrm{dS} \mathrm{m}^{-1}\right)$ e alta $\left(\mathrm{S}_{2}=4,78 \mathrm{dS} \mathrm{m}^{-1}\right)$ salinidade, utilizada para melão Sancho e Medellín (Mossoró, $\mathrm{RN}, 2009)$.

\begin{tabular}{ccccc}
\hline Estratégia & \multicolumn{5}{c}{ Fase fenológica } \\
\cline { 2 - 5 } de manejo & Crescimento & Floração & Maturação & Colheita \\
\hline $\mathrm{T}_{1}$ & $\mathrm{~S}_{1}$ & $\mathrm{~S}_{1}$ & $\mathrm{~S}_{2}$ & $\mathrm{~S}_{2}$ \\
$\mathrm{~T}_{2}$ & $\mathrm{~S}_{2}$ & $\mathrm{~S}_{1}$ & $\mathrm{~S}_{2}$ & $\mathrm{~S}_{2}$ \\
$\mathrm{~T}_{3}$ & $\mathrm{~S}_{2}$ & $\mathrm{~S}_{2}$ & $\mathrm{~S}_{1}$ & $\mathrm{~S}_{2}$ \\
$\mathrm{~T}_{4}$ & $\left(\mathrm{~S}_{1} \text { 2dias }+\mathrm{S}_{2} \text { 1dia }\right)^{*}$ & & \\
$\mathrm{~T}_{5}$ & $\mathrm{~S}_{2}$ & $\mathrm{~S}_{2}$ & $\mathrm{~S}_{2}$ & $\mathrm{~S}_{2}$ \\
\hline
\end{tabular}

* Irrigação com água $\mathrm{S}_{1}$, para dois dias consecutivos, seguida de água $\mathrm{S}_{2}$, por um dia, durante todo o ciclo.

o aparecimento das flores femininas (12-30 dias após a semeadura - DAS), o aparecimento das flores femininas e o início de formação de frutos (30-46 DAS), o início de formação de frutos e o início da maturação (46-60 DAS) e deste até a colheita (60-75 DAS). 
O delineamento experimental utilizado foi o de blocos inteiramente casualizados, em esquema de parcelas subdivididas $6 \times 2$, com quatro repetições, totalizando 24 parcelas (tratamentos de estratégia de manejo), com $96 \mathrm{~m}^{2}$ (8,00 $\mathrm{m} \mathrm{x} \mathrm{12,00} \mathrm{m),} \mathrm{e} 48$ subparcelas (estratégia de manejo x cultivar), com $48 \mathrm{~m}^{2}(8,00 \mathrm{~m} \times 6,00 \mathrm{~m})$. Cada parcela foi composta de quatro fileiras, no espaçamento de $2,0 \mathrm{~m}$ e $0,50 \mathrm{~m}$ entre as plantas, apresentando densidade equivalente a 10.000 plantas ha ${ }^{-1}$. Os tratamentos avaliados foram compostos da combinação de estratégias de manejo da água e cultivares.

O sistema de irrigação utilizado foi o de gotejamento superficial, com gotejadores espaçados em $0,30 \mathrm{~m}$, com vazão da ordem de $1,30 \mathrm{~L} \mathrm{~h}^{-1}$. Foi utilizado um gotejador por planta, formando uma faixa contínua na fileira, após a irrigação. Alâmina aplicada foi determinada diariamente, a partir da evapotranspiração de referência $\left(\mathrm{ET}_{0}\right)$ calculada com os dados climáticos da área, utilizando-se o método do Kc dual (Allen et al. 1998), em que se separa a transpiração da evaporação do solo, conforme a equação $\mathrm{Kc}=$ $\mathrm{Kcb}+\mathrm{Ke}$, em que Kcb = Kc basal, sem evaporação do solo; e $\mathrm{Ke}=$ coeficiente de evaporação do solo.

Os valores de Kcb adotados nas fases de desenvolvimento inicial, intermediária e final foram de 0,$15 ; 1,05$; e 0,75 , respectivamente. Para todas as fases, foram feitas as correções sugeridas por Allen et al. (1998), para ajuste das condições locais de vento, umidade relativa mínima diária e altura de planta, conforme a equação $\mathrm{Kc}($ ajustado $)=\mathrm{Kc}+\left[0,04\left(\mathrm{~V}_{2}-\right.\right.$ 2) $-0,004(\mathrm{URmin}-45)] \mathrm{x}(\mathrm{h} / 3)^{0,3}$, em que $\mathrm{h}=$ altura das plantas (m); $\mathrm{V}_{2}=$ velocidade do vento a $2,0 \mathrm{~m}$ de altura $\left(\mathrm{m} \mathrm{s}^{-1}\right)$; e URmin = umidade relativa mínima diária (\%). Esta equação foi utilizada no cálculo da evapotranspiração máxima da cultura (ETm), que representa a necessidade líquida de irrigação (NLI), da seguinte maneira: $\mathrm{ETm}=\mathrm{NLI}=\mathrm{ETo} . \mathrm{Kc}$, em que $\mathrm{ETm}=\mathrm{NLI}=$ evapotranspiração máxima da cultura $\left(\mathrm{mm} \mathrm{dia}{ }^{-1}\right)$ e $\mathrm{Kc}=$ coeficiente de cultivo.

A necessidade total de irrigação (NTI) foi determinada pela seguinte equação:

$$
N T I=\frac{N L I}{(1-F L) \cdot C U}
$$

em que NTI $=$ necessidade total de irrigação $\left(\mathrm{mm} \mathrm{dia}{ }^{-1}\right) ; \mathrm{CU}=$ coeficiente de uniformidade de aplicação de água do sistema; e FL = fração de lixiviação, considerando-se $(1-F L) . C U$ igual a 0,90 . Em todos os tratamentos, aplicou-se a mesma lâmina de irrigação, porém, com águas de salinidades diferentes, de acordo com o tratamento e a fase da cultura.

Procedeu-se ao preparo do solo de forma idêntica à realizada pela Fazenda Pedra Preta, em seu plantio comercial, que constou de uma aração de disco, à profundidade de $0,40 \mathrm{~cm}$, com posterior gradagem para destorroamento, abertura dos sulcos e construção de leirões, igualmente espaçados em 1,5 m, com dimensões de $1 \mathrm{~m}$ x $50 \mathrm{~m}$, destinados ao plantio.

Com base nos resultados da análise do solo, realizaram-se as adubações, sendo fornecidos $360 \mathrm{~kg} \mathrm{ha}^{-1}$ da formulação 6-24-12, em fundação. A adubação de cobertura foi realizada via fertirrigação, a partir do quinto dia após o transplantio, até a fase final de enchimento dos frutos, e as quantidades de nutrientes aplicados durante o ciclo da cultura foram as seguintes: $\mathrm{N}=107 \mathrm{~kg} \mathrm{ha}^{-1}, \mathrm{P}_{2} \mathrm{O}_{5}=183 \mathrm{~kg} \mathrm{ha}^{-1}$, $\mathrm{K}_{2} \mathrm{O}=235 \mathrm{~kg} \mathrm{ha}^{-1}, \mathrm{~S}=3,45 \mathrm{~kg} \mathrm{ha}^{-1} \mathrm{e} \mathrm{B}=2,65 \mathrm{~kg} \mathrm{ha}^{-1}$. Foram utilizados, como fontes de N, P e K, os adubos $\mathrm{KNO}_{3}$, ureia, ácido nítrico, $\mathrm{KCl}, \mathrm{K}_{2} \mathrm{SO}_{4}, \mathrm{MAP}$ e ácido fosfórico, e, como fontes de micronutrientes, ácido bórico e Quelatec AZ.

A semeadura foi realizada em bandejas de 200 células, com substrato agrícola comercial. Após 10 dias do semeio, efetuou-se o transplantio das mudas para o local definitivo, tendo-se transplantado uma planta por cova, adotando-se o espaçamento de 2,0 m entre as fileiras e $0,40 \mathrm{~m}$ entre as plantas.

Consideraram-se, para medição dos componentes de produção, as duas fileiras centrais de cada parcela, sendo avaliados o número de frutos comerciais (NFCPL) e de frutos totais (NFTPL) por planta, produção comercial (PC) e total (PT) e massa média de frutos comerciais (MMC) e totais (MMT).

A produção total foi determinada pela soma da produção para o mercado externo e interno. Para o mercado externo, foram considerados os frutos intactos, sadios, limpos, com aparência externa uniforme e sem deformações, rachaduras ou sinais de podridão, ataques de insetos, pragas e danos mecânicos, com pesos de 3,65-2,70 kg (tipo 4); 2,70-2,15 kg (tipo 5); 2,10-1,85 kg (tipo 6); e 1,85-1,05 kg (tipo 7). Já para o mercado interno, consideraram-se os frutos com pequenos defeitos de formação ou manchas provocadas pelo sol, do tipo 8, com peso variando entre $1,05 \mathrm{~kg}$ e $0,85 \mathrm{~kg}$. Foram considerados refugo, descartados da produção comercial, os frutos que apresentavam defeitos de formação, injúria mecânica, danos cau- 
sados por pragas ou doenças, indícios de ataque por bactéria ou com tamanho inferior ao exigido pelos mercados externo e interno.

Para as variáveis de qualidade, foram selecionados, ao acaso, dois frutos por parcela, destinados ao mercado externo, para determinação de firmeza da polpa e sólidos solúveis totais. A firmeza da polpa foi determinada por meio da utilização de um penetrômetro manual (McCormick modelo FT 327), com ponteira cilíndrica de $8 \mathrm{~mm}$ ou $12 \mathrm{~mm}$ de diâmetro. Para tanto, o fruto foi partido, longitudinalmente, em duas partes, sendo que, em cada uma delas, foram feitas duas leituras (uma em cada lateral do centro da fatia). As leituras em libras (lb) foram convertidas para Newton (N), multiplicando-as pelo fator 4,4482.

O teor de sólidos solúveis totais (SST) foi determinado com o auxílio de um refratômetro digital (modelo PR-100 Pallete da marca ATAGO), com correção automática de temperatura, e os resultados expressos em percentagem. Em cada metade do fruto que representava uma amostra de cada tratamento, foi retirada uma fatia, no sentido longitudinal. Em seguida, foi realizada a homogeneização das duas fatias de cada fruto, em um liquidificador, sendo o suco obtido após o processamento coado com o auxílio de papel filtro, em bécker, retirando-se, logo após, gotas, para realizar quatro leituras e, assim, obter o valor médio de cada tratamento.

Os dados foram interpretados por meio de análise de variância, realizando-se a comparação de médias entre os tratamentos pelo teste Tukey, a 5\%. Como ferramenta de análise, utilizou-se o programa estatístico Sisvar, versão 4.3 (Ferreira 2000).

\section{RESULTADOS E DISCUSSÃO}

\section{Produção e seus componentes}

De acordo com a análise de variância, para a produção e seus componentes, não houve efeito significativo do fator estratégia de manejo $(p>0,05)$, para a produção comercial (PC) e total (PT), MMC e massa média de fruto total (MFT). Já para o número de frutos comercial (NFC) e total (NFT), ocorreu efeito significativo $(\mathrm{p}<0,05)$, sendo observadas as maiores médias $\left(1,43\right.$ e 1,99 frutos planta ${ }^{-1}$, respectivamente) no tratamento $T_{1}$, que, por sua vez, não diferiu do $\mathrm{T}_{2}, \mathrm{~T}_{4}, \mathrm{~T}_{5}$ e $\mathrm{T}_{6}$ (Tabela 4).

A superioridade do $\mathrm{T}_{1}$, para NFC e NFT, pode ser justificada pelo manejo de irrigação adotado neste tratamento, em que aplicou-se água de baixa salinidade $\left(\mathrm{S}_{1}\right)$ nas fases de crescimento e floração, ou seja, até os 42 DAS, fato que, certamente, favoreceu o pegamento dos frutos.

Conforme relatado por Amor et al. (1999), a redução no número de frutos por planta do meloeiro, quando exposto a alta concentração salina, na fase de floração, é provocada pelo abortamento de flores e/ ou frutos. Os autores constataram que, ao elevar-se a salinidade da água de irrigação de $2 \mathrm{dS} \mathrm{m}^{-1}$ para

Tabela 4. Médias dos números de frutos comercial (NFC) e total (NFT) por planta, produção comercial (PC) e total (PT) e massa média de frutos comercial (MMC) e total (MMT), em função de estratégias de manejo de irrigação com água de baixa $\left(\mathrm{S}_{1}=0,61 \mathrm{dS} \mathrm{m}^{-1}\right)$ e alta $\left(\mathrm{S}_{2}=4,78 \mathrm{dS} \mathrm{m}^{-1}\right)$ salinidade, utilizada na irrigação de meloeiros das cultivares Sancho e Medellín (Mossoró, RN, 2009).

\begin{tabular}{|c|c|c|c|c|c|c|}
\hline \multirow{2}{*}{ Tratamento } & NFC & NFT & $\mathrm{PC}$ & PT & MMC & MMT \\
\hline & \multicolumn{2}{|c|}{ Frutos $\mathrm{pl}^{-1}$} & \multicolumn{2}{|c|}{$\mathrm{Mg} \mathrm{ha}^{-1} \longrightarrow$} & \multicolumn{2}{|c|}{$\mathrm{kg} \mathrm{fruto}^{-1}$} \\
\hline Estratégia de manejo & & & & & & \\
\hline $\mathrm{T}_{1}-\mathrm{S}_{1} \mathrm{~S}_{1} \mathrm{~S}_{2} \mathrm{~S}_{2}$ & $1,43 \mathrm{a}$ & 1,99 a & $36,53 \mathrm{a}$ & $46,06 \mathrm{a}$ & $2,55 \mathrm{a}$ & $2,31 \mathrm{a}$ \\
\hline $\mathrm{T}_{2}-\mathrm{S}_{2} \mathrm{~S}_{1} \mathrm{~S}_{2} \mathrm{~S}_{2}$ & $1,14 \mathrm{ab}$ & $1,55 \mathrm{~b}$ & $32,37 \mathrm{a}$ & $40,67 \mathrm{a}$ & $2,72 \mathrm{a}$ & $2,61 \mathrm{a}$ \\
\hline $\mathrm{T}_{3}-\mathrm{S}_{2} \mathrm{~S}_{2} \mathrm{~S}_{1} \mathrm{~S}_{2}$ & $1,04 \mathrm{~b}$ & $1,63 \mathrm{ab}$ & $30,84 \mathrm{a}$ & $42,20 \mathrm{a}$ & $2,91 \mathrm{a}$ & $2,61 \mathrm{a}$ \\
\hline $\mathrm{T}_{4}-\mathrm{S}_{1} 2 \mathrm{~d}+\mathrm{S}_{2} 1 \mathrm{~d}$ & $1,40 \mathrm{ab}$ & $1,85 \mathrm{ab}$ & $40,42 \mathrm{a}$ & 49,66 a & $2,83 \mathrm{a}$ & $2,69 \mathrm{a}$ \\
\hline $\mathrm{T}_{5}-\mathrm{S}_{2} \mathrm{~S}_{2} \mathrm{~S}_{2} \mathrm{~S}_{2}$ & $1,15 \mathrm{ab}$ & $1,68 \mathrm{ab}$ & $33,86 \mathrm{a}$ & $43,46 \mathrm{a}$ & $2,83 \mathrm{a}$ & $2,56 \mathrm{a}$ \\
\hline $\mathrm{T}_{6}-\mathrm{S}_{0} \mathrm{~S}_{0} \mathrm{~S}_{0} \mathrm{~S}_{0}$ & $1,22 \mathrm{ab}$ & $1,75 \mathrm{ab}$ & $34,92 \mathrm{a}$ & $45,48 \mathrm{a}$ & $2,79 \mathrm{a}$ & $2,60 \mathrm{a}$ \\
\hline \multicolumn{7}{|l|}{ Cultivar } \\
\hline Sancho & $1,26 \mathrm{a}$ & $1,81 \mathrm{a}$ & $33,79 \mathrm{a}$ & $43,78 \mathrm{a}$ & $2,62 \mathrm{~b}$ & $2,42 \mathrm{~b}$ \\
\hline Medellín & $1,20 \mathrm{a}$ & $1,67 \mathrm{~b}$ & $35,86 \mathrm{a}$ & $45,39 \mathrm{a}$ & $2,93 \mathrm{a}$ & $2,71 \mathrm{a}$ \\
\hline CV $1(\%)$ & 21,56 & 14,00 & 24,27 & 17,94 & 11,17 & 11,65 \\
\hline $\mathrm{CV} 2(\%)$ & 19,13 & 12,15 & 18,49 & 12,94 & 5,98 & 6,56 \\
\hline
\end{tabular}

Médias seguidas pela mesma letra, na vertical, não diferem entre si, a $5 \%$, pelo teste Tukey. $\mathrm{S}_{1}=$ água de poço profundo $\left(\mathrm{CE}=0,61 \mathrm{dS} \mathrm{m}^{-1}\right) ; \mathrm{S}_{2}=$ água de poço raso $(\mathrm{CE}=$ $\left.4,78 \mathrm{dS} \mathrm{m}^{-1}\right) ; \mathrm{S}_{0}=$ mistura de $\mathrm{S}_{1} \operatorname{com~}_{2}\left(\mathrm{CE}=3,21 \mathrm{dS} \mathrm{m}^{-1}\right)$. 
$8 \mathrm{dS} \mathrm{m}^{-1}$, aplicada dos 14 dias após o transplantio até a colheita, houve decréscimo na produção comercial de frutos, principalmente devido à redução no número de frutos $(-44 \%)$, ao invés da redução no peso médio do fruto $(-21 \%)$, fato também constatado no presente estudo.

Com base nessa constatação, pôde-se inferir que o meloeiro é mais sensível à salinidade da água de irrigação nas fases de crescimento e floração, concordando com os estudos realizados por Silva et al. (2005), Aragão et al. (2009) e Dias et al. (2010), ao afirmarem que a salinidade elevada do solo, durante o período de floração, reduziu tanto o peso médio dos frutos como o número de frutos planta ${ }^{-1}$, ocorrendo, para este último, com maior intensidade.

Em relação ao fator cultivares, houve efeito significativo apenas para as variáveis NFT, MMC e MMT. Comparando-se as médias das duas cultivares, observou-se que, embora a Sancho tenha apresentando a menor massa média de frutos comerciais e totais, seu número de frutos planta $^{-1}$ foi maior que para a Medellín, indicando que, na fase de início de formação de frutos, esta cultivar é mais sensível à salinidade (Tabela 4). Neste caso, como houve redução no número de frutos, a planta teve menos frutos para os quais disponibilizar nutrientes, sendo, assim, o aumento na massa dos frutos, possivelmente, condicionado a isto, havendo uma compensação da redução no número de frutos. Porém, como os valores médios destas variáveis são absolutos, a diferença encontrada entre as cultivares pode ser atribuída ao fator genético, e não aos efeitos da salinidade, embora estes resultados absolutos sejam importantes na seleção de cultivares tolerantes aos sais.

Não houve efeito da interação dos fatores estratégia de manejo x cultivares, indicando que a tolerância do meloeiro à salinidade não variou entre as cultivares estudadas e que as estratégias de manejo adotadas não interferiram nos componentes de produção entre as cultivares (Tabela 4).

Várias pesquisas têm demonstrado que a tolerância das culturas à salinidade varia entre espécies e cultivares de uma mesma espécie. Para as cucurbitáceas, pôde-se constatar este fato nos trabalhos desenvolvidos por Costa et al. (2010), com as cultivares de melancia Quetzali e Leopard, e por Pereira (2010), com as cultivares de melão Sancho e Medellín (Pele de Sapo), Mandacaru (Amarelo), Néctar (Gália) e Sedna (Cantaloupe).
O estudo conduzido por Kusvuran et al. (2011), com 31 genótipos de melão, mostrou grande variação genotípica do meloeiro, em resposta aos efeitos da salinidade. Segundo Botía et al. (2005), esta variabilidade genética está associada aos mecanismos de adaptação ao estresse salino, desenvolvidos por genótipos de espécies tolerantes aos sais, e, no caso do meloeiro, os autores relatam que as plantas de meloeiro, quando tolerantes à salinidade, acumulam $\mathrm{Na}^{+}$e $\mathrm{Cl}^{-}$no caule, evitando altas concentrações destes íons nas folhas e, consequentemente, a toxidez. Porém, no caso das cultivares estudadas, pode-se afirmar que não há variabilidade genética entre elas associada aos efeitos da salinidade, uma vez que não há diferença significativa entre a interação estratégias de manejo x cultivares.

Assim, a tolerância do meloeiro à salinidade variou com a estratégia de manejo, independentemente das cultivares estudadas, indicando que a tolerância à salinidade varia com o tempo de exposição aos sais e a fase em que esta é aplicada. Estes resultados corroboram os obtidos por Botía et al. (2005), os quais registraram que a salinidade da água de irrigação reduziu o número de flores e retardou a floração do meloeiro, e que a aplicação de água salina, a partir da fase de frutificação, não reduziu a produtividade de frutos comercializáveis, embora tenha melhorado a qualidade dos frutos (sólidos solúveis).

Resultados semelhantes aos desta pesquisa foram obtidos por Porto Filho et al. (2006), avaliando a viabilidade da irrigação do meloeiro amarelo cv. AF646 com águas salinas, em diferentes fases fenológicas, concluindo que o efeito restritivo da salinidade da água de irrigação nos componentes de produção é mais acentuado quando a água salina é utilizada mais cedo.

Observou-se que a estratégia de manejo referente à irrigação com água de baixa salinidade (alto custo de exploração), aplicada durante dois dias, e com água de alta salinidade, por um dia (tratamento $\mathrm{T}_{4}$ ), destacou-se na produção total e comercial de frutos do meloeiro, proporcionando economia de, aproximadamente, $33 \%$ de água de baixa salinidade, o que poderá ser uma estratégia de manejo de irrigação economicamente viável. O fato de a irrigação com água salina viabilizar a produção de melão mostra que a água salina é um recurso potencial para a irrigação em áreas semiáridas do Nordeste do Brasil. 


\section{Qualidade pós-colheita dos frutos}

Para as características de qualidade pós-colheita, observou-se efeito significativo tanto entre estratégias de manejo como entre as cultivares, para sólidos solúveis ( $\mathrm{SS}$ ) e firmeza de polpa (FP), e não significativo para a interação estratégia de manejo $\mathrm{x}$ cultivar (Tabela 5).

Para os SST, os tratamentos $\mathrm{T}_{1}, \mathrm{~T}_{2}, \mathrm{~T}_{4} \mathrm{~T}_{5} \mathrm{e}$ $\mathrm{T}_{6}$ não diferiram, estatisticamente, entre si, sendo os maiores valores observados no tratamento $T_{5}$ $(11,80 \%)$, em que houve irrigação com água salina continuamente, durante todo o ciclo, seguido do $\mathrm{T}_{2}$ $(11,48 \%)$ e $\mathrm{T}_{1}(11,12 \%)$, os quais foram irrigados com água salina a partir da fase de formação de frutos. Para estes tratamentos, os valores de SS ( ${ }^{\circ}$ brix) superaram o valor mínimo exigido pelo mercado externo, para o melão Pele de Sapo, que é de 11\% (Menezes et al. 2000). Estes resultados estão em acordo com os apresentados por Gurgel et al. (2005), que, também, verificaram aumento significativo nos SS, com o aumento da salinidade. Já Porto Filho et al. (2009) não observaram, em estudo semelhante a este, embora com outra cultivar, efeito significativo para SS e firmeza de polpa (FP).

A aplicação de água de baixa salinidade, na fase de formação de frutos, reduziu os SST (10,47\%), fato observado no tratamento $\mathrm{T}_{3}$. Com relação ao

Tabela 5. Médias de sólidos solúveis e firmeza de polpa de frutos, em função de estratégias de manejo de irrigação com água de baixa $\left(\mathrm{S}_{1}=0,61 \mathrm{dS} \mathrm{m}^{-1}\right)$ e alta $\left(\mathrm{S}_{2}=4,78 \mathrm{dS} \mathrm{m}^{-1}\right)$ salinidade, utilizada na irrigação de meloeiros das cultivares Sancho e Medellín (Mossoró, RN, 2009).

\begin{tabular}{lcc}
\hline \multirow{2}{*}{ Tratamento } & $\begin{array}{c}\text { Sólidos } \\
\text { solúveis totais }\end{array}$ & $\begin{array}{c}\text { Firmeza de } \\
\text { polpa }\end{array}$ \\
\cline { 2 - 3 } & $\%$ & $\mathrm{~N}$ \\
\hline Estratégia de Manejo & & \\
$\mathrm{T}_{1}-\mathrm{S}_{1} \mathrm{~S}_{1} \mathrm{~S}_{2} \mathrm{~S}_{2}$ & $11,12 \mathrm{ab}$ & $23,32 \mathrm{ab}$ \\
$\mathrm{T}_{2}-\mathrm{S}_{2} \mathrm{~S}_{1} \mathrm{~S}_{2} \mathrm{~S}_{2}$ & $11,48 \mathrm{ab}$ & $22,41 \mathrm{~b}$ \\
$\mathrm{~T}_{3}-\mathrm{S}_{2} \mathrm{~S}_{2} \mathrm{~S}_{1} \mathrm{~S}_{2}$ & $10,47 \mathrm{~b}$ & $24,57 \mathrm{a}$ \\
$\mathrm{T}_{4}-\mathrm{S}_{1} 2 \mathrm{~d}+\mathrm{S}_{2} 1 \mathrm{~d}$ & $10,87 \mathrm{ab}$ & $23,87 \mathrm{ab}$ \\
$\mathrm{T}_{5}-\mathrm{S}_{2} \mathrm{~S}_{2} \mathrm{~S}_{2} \mathrm{~S}_{2}$ & $11,80 \mathrm{a}$ & $23,19 \mathrm{ab}$ \\
$\mathrm{T}_{6}-\mathrm{S}_{0} \mathrm{~S}_{0} \mathrm{~S}_{0} \mathrm{~S}_{0}$ & $10,65 \mathrm{ab}$ & $24,09 \mathrm{a}$ \\
\hline Cultivares & & \\
Sancho & $11,42 \mathrm{a}$ & $22,42 \mathrm{~b}$ \\
Medellín & $10,72 \mathrm{~b}$ & $24,73 \mathrm{a}$ \\
\hline CV 1 $\%)$ & 7,32 & 4,04 \\
\hline CV 2 (\%) & 5,15 & 5,85 \\
\hline
\end{tabular}

Médias seguidas pela mesma letra, na vertical, não diferem entre si, a $5 \%$, pelo Teste Tukey. $\mathrm{S}_{1}=$ água de poço profundo $\left(\mathrm{CE}=0,61 \mathrm{dS} \mathrm{m}^{-1}\right) ; \mathrm{S}_{2}=$ água de poço raso $\left(\mathrm{CE}=4,78 \mathrm{dS} \mathrm{m}^{-1}\right) ; \mathrm{S}_{0}=$ mistura de $\mathrm{S}_{1} \operatorname{com~} \mathrm{S}_{2}\left(\mathrm{CE}=3,21 \mathrm{dS} \mathrm{m}^{-1}\right)$. fator cultivares, concluiu-se que a cultivar Sancho apresentou valores de SS superiores aos da Medellín, com médias de $11,42 \%$ e $10,72 \%$, respectivamente.

Dias et al. (2010) constataram que os níveis de salinidade da solução nutritiva afetaram, significativamente $(\mathrm{p}<0,05)$, a qualidade química dos frutos, no que se refere aos conteúdos médios de SS, observando acréscimo linear desta variável, com o incremento da CE da solução.

Zong et al. (2011) também observaram efeitos da salinidade na produção e qualidade de duas espécies de cucurbitáceas chinesas. Para o melão (cv. Huanghe), os autores registraram decréscimo na produtividade e no teor de ácido glutâmico, à medida em que se aumentou a salinidade da água de irrigação, embora a concentração da maioria dos aminoácidos não tenha diferido significativamente. Já o rendimento da melancia (Citrullus lanatus. convar megulaspemus) diminuiu significantemente, com o incremento da salinidade da água, enquanto o número de frutos, firmeza de polpa, teor de proteína bruta e aminoácidos essenciais da melancia aumentaram significativamente, com o incremento da salinidade da água. De acordo com os autores, o estresse salino, em ambas as espécies de cucurbitáceas, resultou em aumento no teor de SS.

Medeiros et al. (2008) observaram, estudando três níveis de salinidade de água de irrigação em campo, efeito linear positivo sobre os SST dos frutos do meloeiro, em virtude do incremento da salinidade. Por outro lado, Dias et al. (2005) concluíram que a tendência foi diminuir, de $11,4 \%$ para $10,8 \%$, o conteúdo de SST, ao se aumentar a salinidade da água de irrigação, ou seja, o estresse osmótico reduziu o conteúdo de sólidos solúveis dos frutos de meloeiro rendilhado (cv. Bônus II).

Em muitos países, os teores de SS adotados como referência de mercado variam de 8 a $10^{\circ}$ Brix (Morais et al. 2009). Com base nesta constatação, apenas os frutos das plantas nutridas com solução de $7 \mathrm{dS} \mathrm{m}^{-1}$ apresentaram valores médios de SS abaixo do mínimo exigido pelo mercado.

Não houve efeitos significativos dos fatores estratégia de manejo e cultivar (Tabela 5), para a firmeza de polpa (FP) dos frutos de melão, não havendo interação tratamento x cultivar significativa. A média da FP, para a estratégia de manejo $\mathrm{T}_{2}$ (água boa na fase de floração e água salobra nas demais fases), diferiu, estatisticamente, das demais, sendo estas iguais estatisticamente. Dentre as cultivares, registraram-se 
médias de FP iguais a $24,73 \mathrm{~N}$ e $22,42 \mathrm{~N}$, para as cultivares Medellín e Sancho, respectivamente. Esta diferença está associada, provavelmente, à diferença genética entre as cultivares, tendo a Medellín maior expressão para produzir frutos com maior firmeza. Estes valores de FP, obtidos neste estudo, ficaram um pouco abaixo da exigência do mercado para exportação, que é de $32 \mathrm{~N}$, o que pode estar relacionado ao atraso em que se deu a colheita dos frutos, a qual foi realizada cinco dias após os frutos já estarem no ponto de colheita.

As perdas ocorridas na produção do meloeiro refletem o efeito negativo do potencial osmótico da solução salina do solo, devido ao estresse salino sobre o crescimento das plantas, uma vez que este estresse reduz o potencial hídrico, diminuindo a absorção de água pelas plantas, bem como a capacidade fotossintética, devido a vários fatores, como desidratação das membranas celulares, toxicidade por sais, redução no suprimento de $\mathrm{CO}_{2}$ (fechamento de estômatos), senescência induzida pela salinidade e mudança na atividade das enzimas (Iyengar \& Reddy 1996).

\section{CONCLUSÃO}

A irrigação com água de boa qualidade, aplicada durante dois dias, seguida da irrigação com água salina, por um dia, viabilizou a produção comercial de melão, com redução de $33 \%$ no uso da água de boa qualidade.

\section{REFERÊNCIAS}

ALLEN, R. G. et al. Crop evapotranspiration: guidelines for computing crop water requirements. Rome: FAO, 1998. (Irrigation and drainage, 56).

AMOR, F. M. del et al. Salinity duration and concentration affect fruit yield and quality, and growth and mineral composition of melon plants grown in perlite. Hortscience, Alexandria, v. 34, n. 7, p. 1234-1237, 1999.

ARAGÃO, C. A. et al. Avaliação de cultivares de melão sob condições de estresse salino. Revista Caatinga, Mossoró, v. 22, n. 2, p. 161-169, 2009.

BOTÍA, P. et al. Yield and fruit quality of two melon cultivars irrigated with saline water at different stages of development. European Journal of Agronomy, Taastrup, v. 23, n. 3, p. 243-253, 2005.

CARMO FILHO, F.; OLIVEIRA, O. F. Mossoró: um município do semiárido nordestino, caracterização climática e aspecto florístico. Mossoró: ESAM, 1995.
COSTA, A. R. F. C. et al. Produção de cultivares de melancia submetidas a níveis de salinidade da água de irrigação e doses de nitrogênio. Revista Brasileira de Agricultura Irrigada, Fortaleza, v. 4, n. 4, p. 242-248, 2010.

COSTA, M. E. da et al. Estratégias de irrigação com água salina na mamoneira. Revista Ciência Agronômica, Fortaleza, v. 44, n. 1, p. 34-43, 2013.

DIAS, N. S. et al. Calidad post-cosecha de frutos de melón producidos sobre diferentes niveles de salinidade del suelo y manejos de la fertirrigación en invernadero. Ingeniería del Agua, Córdoba, v. 12, n. 2, p. 119-123, 2005.

DIAS, N. S. et al. Produção de melão rendilhado em sistema hidropônico com rejeito da dessalinização de água em solução nutritiva. Revista Brasileira de Engenharia Agrícola e Ambiental, Campina Grande, v. 14, n. 1, p. 1-5, 2010.

DIAS, N. S. et al. Concentração salina e fases de exposição à salinidade do meloeiro cultivado em substrato de fibra de coco. Revista Brasileira de Fruticultura, Jaboticabal, v. 33, n. 3, p. 915-921, 2011.

EDELSTEIN, M. et al. Boron and salinity effects on grafted and non-grafted melon plants. Plant and Soil, Crawley, v. 269, n. 1-2, p. 273-284, 2005.

EMPRESA BRASILEIRA DE PESQUISA AGROPECUÁRIA (Embrapa). Sistema brasileiro de classificação de solos. Brasília, DF: Embrapa Produção de Informação, 1999.

FERREIRA, D. F. Manual do sistema Sisvar para análises estatísticas. Lavras: UFV, 2000.

FERREIRA NETO, M. et al. Emissão foliar, relações iônicas e produção do coqueiro irrigado com água salina. Ciência Rural, Santa Maria, v. 37, n. 6, p. 1675-1681, 2007.

GURGEL, M. T. et al. Produtividade de duas cultivares de meloeiro irrigadas com água de alta e baixa salinidade. Revista Brasileira de Engenharia Agrícola e Ambiental, Campina Grande, v. 9, supl., p. 318-321, 2005.

KUSVURAN, S. et al. Determination of genotypical differences of melons to salt tolerance. Acta Horticulturae, Lisbon, v. 918, n. 2, p. 777-783, 2011.

MEDEIROS, D. C. et al. Produção de melão Pele de Sapo híbrido 'Medellín' cultivado com diferentes salinidades de água. Revista Ciência Agronômica, Fortaleza, v. 42, n. 3, p. 628-634, 2011.

MEDEIROS, J. F.; DIAS, N. S.; BARROS, A. D. Manejo da irrigação e tolerância do meloeiro à salinidade da água de irrigação. Revista Brasileira de Ciências Agrárias, Recife, v. 3, n. 3, p. 242-247, 2008. 
MEDEIROS J. F. et al. Caracterização das águas subterrâneas usadas para irrigação na área produtora de melão da Chapada do Apodi. Revista Brasileira de Engenharia Agrícola e Ambiental, Campina Grande, v. 7, n. 3, p. 469-472, 2003.

MENEZES, J. B. et al. Características do melão para exportação. In: ALVES, R. E. (Ed.). Melão: pós-colheita. Brasília, DF: Embrapa Comunicação para Transferência de Tecnologia, 2000. p. 13-22.

MORAIS, P. L. D. et al. Avaliação das tecnologias póscolheita utilizadas e da qualidade de melões nobres produzidos para exportação. Ciência e Tecnologia de Alimentos, Campinas, v. 29, n. 1, p. 214-218, 2009.

PEREIRA, F. A. L. Tolerância de cultivares de melão à salinidade. 2010. 76 f. Dissertação (Mestrado em Irrigação de Drenagem) - Universidade Federal Rural do Semiárido, Mossoró, 2010.

PORTO FILHO, F. Q. et al. Evolução da salinidade e do pH de um solo sob cultivo de melão irrigado com água salina. Revista Brasileira de Engenharia Agrícola e Ambiental, Campina Grande, v. 15, n. 11, p. 1130-1137, 2011.

PORTO FILHO, F. Q. et al. Qualidade de frutos do melão amarelo irrigado com água de diferentes níveis de salinidade. Revista Caatinga, Mossoró, v. 22, n. 1, p. 193-198, 2009.

PORTO FILHO, F. Q. et al. Viabilidade da irrigação do meloeiro com águas salinas em diferentes fases fenológicas. Ciência Rural, Santa Maria, v. 36, n. 2, p. 453-459, 2006.
RICHARDS, L. A. Diagnosis and improvement of saline and alkali soils. Washington, DC: USDA, 1954. (Agriculture handbook, 60).

SAVVAS, D. et al. Interactions between salinity and irrigation frequency in greenhouse pepper grown in closed-cycle hydroponic systems. Agricultural Water Management, Amsterdam, v. 91, n. 1-3, p. 102-111, 2007.

SILVA, M. M. C. et al. Produtividade de frutos do meloeiro sob diferentes níveis de salinidade da água de irrigação, com e sem cobertura do solo. Horticultura Brasileira, Brasília, DF, v. 23, n. 2, p. 202-205, 2005.

SOARES, T. M. et al. Produção de alface utilizando águas salinas em sistema hidropônico. Revista Irriga, Botucatu, v. 12, n. 2, p. 235-248, 2007.

TERCEIRO NETO, C. P. C. et al. Acúmulo de matéria seca e nutrientes no meloeiro irrigado sob estratégias de manejo da salinidade. Revista Brasileira de Engenharia Agrícola e Ambiental, Campina Grande, v. 16, n. 10, p. 1069-1077, 2012.

IYENGAR, E. R. R.; REDDY, M. P. Photosynthesis in highly salt tolerant plants. In: PESSARAKLI, M. (Ed.). Handbook of photosynthesis. Baten Rose: Marshal Dekar, 1996. p. 897-909.

ZONG, L. et al. Effect of different irrigation water salinities on some yield and quality components of two field-grown cucurbit species. Turkish Journal of Agriculture and Forestry, Ankara, v. 35, n. 2, p. 297-307, 2011. 